\title{
Internet as System and Environment in Cyberspace: Preliminary Ideas from an Ongoing Research
}

\author{
Marcos Palacios
}

Department of Communication, Universidade Federal da Bahia, Campus Universitário de Ondina, Salvador, Brazil, palacios@ufba.br

\begin{abstract}
The paper discusses the applicability of a pair of concepts - System/Environment - to Internet and Cyberspace. A central point in the discussion is that the pair System/Environment should not be viewed as static analytical poles, but rather as dynamic and interchangeable elements, so that Internet can be conceived both as System and/or Environment, depending on the type of phenomenon one is observing. As a counterpoint to this proposition, the recurrent and "common-sense" notion of Internet as a new medium is presented and criticized. The article also discusses and puts under critical scrutiny the role usually assigned to Internet as a change catalyst or accelerator and the implicit or explicit acceptance of an evolutionary new step in social organization represented by the generalization of New Technologies of Communication. The paper is part of an ongoing research on Digital Cities and Local Networks and proposes some initial steps towards the construction of a model of interpretation based on systems analysis adapted to the particularities of Internet and Cyberspace. The research is anchored on
\end{abstract}

observations of Digital Cities and Local Networks projects at Internet, with special attention to the Aveiro Digital City Project (Portugal).

Keywords: Digital Cities, Local Networks, Systems Analysis, Internet, Aveiro Digital City, Cyberculture

Acknowledgement: An earlier version of this paper was presented at the 23rd. IAMCR Conference, Barcelona. It outlines some working ideas and preliminary conclusions from research done at Universidade de Aveiro, Portugal, jointly financed by ICCTI (Instituto de Cooperação Científica e Tecnológica Internacional) of Portugal and CAPES (Coordenação de Aperfeiçoamento de Pessoal de Nível Superior) of Brazil. Continuity for the research has now been made possible through a CNPq (Conselho Nacional de Desenvolvimento Científico e Tecnológico) grant.

\section{Introduction}

As a variety of experiments proliferate around the world involving the creation and administration of socalled Digital Cities and Local Networks, a very rich field of observation is laid open for research, involving new forms of community formation and management, public decision making and budget administration, political transparency and democracy, access to education and other public resources, new approaches to urban planning, and many other themes related to applied social sciences and economics. Made possible by the creative application of New Technologies of Communication in general, and Internet resources in particular, the now widespread phenomenon of Digital Cities also offers opportunities for theoretical analyses which may help to further the conceptual understanding of such technologies.

This preliminary and exploratory paper, originates from observations and reflections centred on practical experiments involving the creation and administration of Digital Cities and aims to raise questions concerning some theoretical aspects of Internet and the so called New Technologies of Communication ${ }^{1}$. It specifically suggests the applicability of a dynamic version of the concepts of System and Environment

\footnotetext{
${ }^{1}$ The word New in this context has caused of a lot of controversy, but this paper does not engage in that debate and the term is used as it currently appears in most of the literature, as a synonym for electronic and digital/informational communication technologies.
} 
to Internet and Cyberspace, as an alternative to a current, - and in our view more limited -, analytical approach which characterizes Internet and Cyberspace solely as a new media.

Cyberspace can be defined as a combination of telecommunications capabilities, computer mediated communications and virtual reality technologies, in a conjunction of Informatics and Telecommunications, thus resulting in the neologism Telematic Technologies used throughout the paper.

It is a basic premise of this paper that in contemporary (information) society, social organizations and institutions of all types (commercial, educational, juridical, financial, criminal, political, etc) have virtual extensions into Cyberspace. Such extensions should be viewed as integral, symbiotic (Kitchin 1998) and in most cases now - vital elements of contemporary institutions and social practices. And in some cases the situation becomes reversed, so that it is the "physical" side of the organization that could be viewed as "extensions", as in the case of big Internet services providers, such as AOL or Terra, maintaining stores in shopping centres for the selling of their services.

A survey of the available recent literature seems to indicate a progression concerning the discussion on the implementation of Digital Cities and Local Networks (Schwartz 2001). From an initial stage that emphasized technological obstacles for the materialization of such projects (access to computers, terminals, servers), the discussion has shifted towards the identification of socio-cultural obstacles (educational standards; digital literacy; differential capacity to look for, select and use information; free time availability), that lay beyond the purely technological or economical limitations of the potential users' physical access to a workstation ${ }^{2}$ and can undermine the implementation and/or generalization of digital citizenship.

Is it also necessary to consider another set of problems, under the general classification of demand and motivation issues: which needs are being contemplated in a Digital City project? Who determines the hierarchy of needs to be assisted? What are the relevant criteria? In other words, in addition to having physical access to a workstation, the potential telematic citizen must know how to efficiently use the resources made available by the project, how to navigate in the virtual city and, above all, he/she must want to be a digital citizen and participate in the project.

The needs and motivations of the potential Digital Cities users are centrally related to the issue of the quantity and quality of material (contents) available in the Web, for specific use(r)s. The concern with contents has come to occupy a prominent place in analyses dealing with the use of telematic networks in urban planning, reinforcing the importance of creation of locally relevant materials and spaces for expression (Graham 2000; Graham/Marvin 1999). To ignore such crucial problems can lead to selective integration (Castells 1998), growth of polarization and digital exclusion (Wolton 1999a). Some aspects of these issues have been discussed in a paper reporting an empirical and quantitative mapping out of the material in Portuguese available in the Internet (Palacios 2000:186-203).

However, the treatment of those empirical themes emerging from the proliferation of Digital Cities in the Web demands the use of more elaborated theoretical frameworks for the sociological characterization of the networks that serve as scenarios for such experiments, and of the social processes that take place within cyberspace. An attempt will be made to move forward and offer some suggestions in that direction.

\section{Point of Reference}

The main concrete point of reference for this paper is the Aveiro Digital City Program (ADCP), an ongoing Portuguese Digital City project ${ }^{3}$, defined as an effort to "mobilize and generalize in society the instruments, techniques and forms of organization, information, communication, knowledge and action of advanced societies". It is a long-term project, using Telematic Technologies and involving a group of subprojects. It is conceived as a tool for social mobilization and modernization. According to the project's official definition, "in addition to providing infrastructures and systems, the construction of the Digital City

\footnotetext{
2 See for instance the positions sponsored by the Digital Divide Network in: http://www.digitaldividenetwork.org/

${ }^{3}$ The city of Aveiro is located in North-Western Portugal and has a population of around 75 thousand inhabitants.
} 
aims at a radical transformation of habits and patterns of behaviours, both of the citizens and of the institutions that make the city" (ADCP 1999).

The creation of a Digital City is, by definition, an experimental activity. The concept of Digital City itself should be under continuous discussion, elaboration and revision, throughout the experiment. That insight can be identified in the text of the Aveiro Digital City Project (ADCP), as it defines the development of the concept of Digital City as one of its objectives.

Preliminarily, it is essential to have in mind that in the case of multifaceted projects, like the ADCP, Internet and its applications constitute just one of their dimensions. In addition to Internet, the ADCP involves, in its first phase of implementation, the creation and development of intranets (e.g. the linking of the hospitals and the city's health centres, or the libraries and public archives), direct applications of telematic technologies to urban equipments (e.g. monitoring of urban public transport or environmental quality), creation of points of public access (telecentres, electronic city information kiosks), financing and encouragement of educational programs.

In order to deal with those different dimensions of a complex Digital City project like the ADCP, a fitting and opportune analytical distinction was established by Branco and Mamede (2002) between the Webcity (the Internet component of a Digital City Project) and the Digital City itself (the complete project, comprising virtual and physical dimensions). This paper adopts Branco and Mamede's terminology and therefore the term Webcity should be here understood as the Internet component of a Digital City.

It is evident that a Webcity can exist and thrive without any connection to a physical urban space (Palacios 2002a). As a matter of fact, even Cybernations, without any relation to physical, geo-political countries, can be found in the Net, as in the case of Ladonia (http://www.ladonia.net) and many others ${ }^{4}$. However, those are not the experiments that serve as background for the ideas discussed in this paper, but rather the anchored or grounded Webcities, that have been created as integral part of physical urban spaces (Lemos 2001; Aurigi/Graham1998), as in the case of the ADCP. In this sense, Digital Cities can be equated with Local Networks, or rather with systems of integrated Local Networks.

Branco and Mamede (2002) use a slightly modified version of the three-layered model proposed by Ishida (2000), and establish three media functions for the Webcity:

- Interaction function (social interaction among citizens and/or tourists and authorities);

- Interface function (maps and graphics; access; navigation and "displacement" in the city);

- Information function (digital files and urban data in real time).

Starting from those three basic functions, Branco and Mamede try to locate and analyze them in the concrete cases of Aveiro and Bragança, two Portuguese cities engaged in the implementation of their respective Digital Cities projects. Although the resulting exercise is useful and may help to understand the role of Internet in a Digital City project, its main shortcoming is that the functions thus established are defined from purely technical criteria.

As pointed out by Branco and Mamede themselves, Webcities constitute "a digital medium whereby the articulation of physical space and cyberspace is achieved, preserved the specific characteristics of each one" ${ }^{5}$. However, grounded Webcities, should, at least in theory, maximize participatory mechanisms and processes among citizens of the physical cities to which they are anchored, and so they should be thought as mechanisms capable of "creating community synergies, aiding the planning and execution of common projects, creating effective channels with public authorities and, perhaps, even reheating the physical spaces for citizens participation" (Lemos 2001).

There is, therefore, in this type of Digital City experiments, a political dimension that precedes technical functions and should serve as point of reference for them. The political dimension has to be discussed in the light of an understanding of the operation and of the specificities of the telematic networks while spaces for socialization and social action. It is claimed in this paper that a characterization of Internet as a medium, as an "articulation mechanism" between cyberspace and physical space, is too limited and needs to be qualified and enlarged, in order to provide us with a more comprehensive theoretical framework for

\footnotetext{
${ }^{4}$ For a discussion of Cybernations in the Web see Lemos (2001b).

${ }^{5}$ In the original in Portuguese: "um medium digital onde se dá a articulação do espaço físico com o ciberespaço, guardadas as devidas características de cada um" (p.2).
} 
the analysis of the place and function of the telematic technologies in the constitution and operation of contemporary societies.

\section{In Search of Characterizations}

An initial attempt will be made to clarify and, hopefully, broaden the notion of medium, in the context of the new technologies of information and communication. A seemingly appropriate starting point is the distinction established by Dominique Wolton (1999a) between a logic of offer that characterizes traditional media (radio, TV, the press) based on the centralized emission of messages for massive audiences (the so called One $\Leftrightarrow$ All model) and a logic of demand that characterizes the New Technologies of Communication, based on decentralized production and individualized access to messages (the so-called All $\Leftrightarrow$ All model $)^{6}$.

Such media modalities are seen by Wolton not as ascending points along a progressive evolutionary scale, but as complementary formats, a view which he shares with many communication researchers, at least since the seminal works by Marshall McLuhan back in the 1960's and 70's. He calls attention to the enormous capacity of the New Technologies of Communication to act as support for information and databases, but he points out that such a mass of information requires, on a growing scale, professional processes of filtering, selection, and validation:

"Direct communication, without mediation, as a technical performance. That appeals for dreams of individual freedom, but it is illusory. The Net can give access to a mass of information, but nobody is a citizen of the world, wanting to know everything, about everything, in the whole world. The more information there is, the more we need middlemen journalists, archivists, editors, etc - that filter, organize, prioritise. No one wants to play the newspaper chief editor's role every morning. Equality of access to information doesn't create equality of use of information. To confuse (equality of access with equality of use) is techno-ideology" (Wolton 1999c).

The scenario of the disappearance of journalism (or at least the waning of journalists as middlemen), suggested by Pierre Levy (1997, Chapter 13), as a consequence of the development of Internet and Digital Cities sounds, more and more, as an unacceptable simplification ${ }^{7}$.

Niklas Luhmann also stresses the idea that the evolution of media processes does not take place in a mechanical, phase-like fashion :

"It would be a serious mistake to suppose that community life previous to language was replaced by a language of oral use, this in turn by writing, writing by printing and printing by electronics means. A phase-like model of this type would be a total simplification. One cannot speak at all of relegation nor of substitution. In each new phase of evolution, the precedent form is preserved and it is only complemented by new possibilities" (Luhmann 1992: 51)

The logic of demand that characterizes the new media raises a series of problems that should be taken into consideration when one discusses the creation and management of Digital Cities. In the first place, the logic of demand tends to favour the use of new media by specialized groups (e.g. academics or professionals) and the creation of all types of specialized Virtual Communities, focused on specific and

\footnotetext{
${ }^{6}$ The bi-directional symbol $(\Leftrightarrow)$ is used to characterize both models (and not just the $A l l \Leftrightarrow A / l$ because in the One $\Leftrightarrow$ All model reception processes and their effects have to be taken into account and therefore it would be inaccurate to portray information exchange as uni-directional flows in any communicational model, as reception necessarily affects the production of messages.

7 It could also be argued that Levy's suggestion of the coming demise of "classical journalism" is a consequence of his biased characterization of journalists as no more than "reducers to common denominators".
} 
sometimes even hyper specialized subjects (e.g. cardiology, aquatic gardening, metallic rock, exotic birds breeding, the early works of Jean Paul Sartre, and so on, etc.), leading to a fragmentation of society into communities of interest that may cohabit with total mutual indifference (Weinreich 1997), thus increasing polarizations and disparities, instead of reducing them.

On the other hand, the logic of demand characterizes the new media as technologies centred on the individual. In normal circumstances, Internet navigation is a lonely act, performed by the user in front of a computer. That centring on the individual can be detected in the representation of the Web among Internet users. In his research on the use of Internet in secondary schools of Quebec, Jacques Piette collected among the students expressions that are recurrent among Web users:

"Moi, je suis tout seul avec Internet." Les jeunes nous donnent souvent cette image-là. Ils aiment bien l'image de navigation. Ça marche très bien. Ils disent : "Oui, Internet, je navigue. C'est moi qui suis le capitaine" et "C'est moi qui choisis, mais c'est moi tout seul" dans un rapport totalement individuel, et les dimensions sociales, communautaires s'estompent" (Piette 1998)8.

From a dichotomized media typology (logic of offer and logic of demand) and in view of the premise of the complementarity between traditional and New Technologies of Communication, Dominique Wolton (1999b) invites his readers to "abandon the war of media" and alerts them to "the necessity of preserving mass media and mass culture as one of the conditions for cultural equality".

\section{Beyond the Dichotomy: Hybrid Networks?}

Although the above discussed dichotomy may enlarge our understanding of the working logic of Internet and other communicational and telematic technologies, it still maintains the reduction of Internet to a medium, resulting in a characterization that we consider insufficient and partial.

The notions of medium and mediation are associated to processes of transmission/exchange of messages. Mediation processes indeed take place at Internet, especially when that mediation is conceived in broader terms as "articulation between physical space and cyberspace" (Branco/Mamede 2002: 92). However, it also seems evident that "mediation", even in the last wider sense, does not exhaust and does not appropriately describe the totality of processes that can be detected and observed, when one refers to Internet in its actual functioning, as in the context of Digital Cities.

In characterizations of the Internet as a medium, the Net is defined as a communication system, comparable to other communication systems, as it is clear e.g. in Wolton's typology of individualized communication, community communication and mass communication. The differences and specificities of such communication systems, according to Wolton, would be established by their character (massive or non-massive) and by the type of logic (offer or demand) presiding their functioning. All this can be valid, but it is still insufficient for a more comprehensive characterization of the place and role of Internet within ongoing Digital Cities projects, with their networks of physical and virtual spaces.

One faces therefore a preliminary difficulty of how to portray that complex network that constitutes the Digital City, with its array of integrated Local Networks, and in which Internet, being a mediation element, cannot be conceived as mere support or as nothing else but an instrumental medium for the establishment of connections among actors.

It is suggested here that (among many other possible pathways to be explored) a notion that offers interesting possibilities for the description of the complexity observed in the Digital Cities and Local Networks - and other cyberspace applications - was proposed by Thierry Bardini in his studies on

\footnotetext{
8 "I am absolutely by myself in the Internet". The youngsters often give us this image. They love the image of navigation. It works very well. They say: "It is me who chooses, myself and nobody else" in a totally individual relationship, and the social, community dimensions vanish."
} 
technological change and diffusion, through the concept of Hybrid Networks (reseaux hybrides), composed by human (actors) and non-human (actants) participants:

"It is necessary to replace the outdated (mediation) conception of human actors instrumentally and materially linked, by a mediation conception in which everything is a hybrid network, i.e. groups of more or less stable associations among humans and non-humans, in which the actors' and actants' "presence" can vary in a continuum that goes from physical and concrete presence to existence as discourse". (Bardini 1996:137)

It should be kept in mind, of course, that such a definition was proposed as a general conception that refers to all types of socio-technical networks (réseaux socio-techniques) that are established in processes of creation and diffusion of technological innovations, that are the phenomena under investigation in Bardini's writings. However, nothing seems to preclude its application to the situation of a Digital City, and other cyberspace applications. Under that light, the articulation between physical space and cyberspace (mediation), could be characterized as one of the functions of Internet within the Digital City's hybrid network, although not necessarily its only function.

On the other hand, Bardini's definition is broad enough to encompass not only the technological and material aspects of a network, but also its representations (its "existence as discourse") which are very often ignored when one deals with complex networks and New Technologies of Communication, despite the fact that it should by now be evident that the imaginary occupies an essential place in terms of the actions both of creators and users of any technique (Flichy 2001: 254-61; Loureiro da Silva 2002: 133149).

\section{Networks, Systems and Shared Environments}

To enlarge the scope of this discussion and try to move a little further, it may be useful to consider a notion proposed by Gottfried Stockinger. Discussing contemporary information societies, he suggests that "cyberspace and specifically the Net on the one hand and the social organizations (e.g. companies, teams, departments, political parties) on the other hand, form co-systems, acting mutually as environment (...) " (Stockinger 2001: 107). The expression co-systems indicates that a system evolves in parallel with another system, and that they act mutually as environment to each other, thus increasing their selfregulatory potentials (Stockinger 2001: 130).

Despite reservations one may have concerning the use of the expressions "on the one hand" and "on the other", as such formulation seems to weaken the idea of the existence of a continuum between physical space and cyberspace, Stockinger's notion is very fertile as it allows one to conceive the continuum physical/virtual space in systemic terms and may help to build images of its dynamics.

Although it is obviously impossible, in the scope of this paper, to outline the historical trajectory of the conceptual pair system/environment in the traditions of sociology and systems analysis, some presuppositions for the appropriation of those concepts can be established.

First of all, it has to be pointed out that the complementarity between system and environment is a common trait of all schools and traditions of systems analysis. There is no system without environment. Such a postulate is integrally assimilated in the present perspective.

Secondly, converging with Luhmann's and Stockinger's positions and arguing against the static distinction ("interpenetration of sub-systems"; "shared common areas") established by classical systems theory between open and closed systems (e.g. Parsons 1974: 17), it is here sustained that the borders between system and environment are always mobile and fluid, as paradoxically every system is simultaneously closed (e.g. the juridical or the economical system) and open, in the sense that any system is capable to relate to the environment in order to process information and to develop.

Considering that fluidity of borders between system and environment, it is possible to understand that the different (sub-)systems contained in a hybrid network can be exchanged, amongst themselves, as 
environment. To exemplify: a system of journalistic information (online newspaper) can become (be used as) an environment for a web-based educational system (online university) as it offers first hand data that can be used as input for courses, seminars, research; on the other hand, the web-based educational system (online university) plays the role of environment for the journalistic information system (online newspaper) as it serves as a source for "news" concerning the academic and scientific world, and thus "feeds" the journalistic system.

Systems and environments should therefore not, under any hypothesis, be conceived as fixed poles. On the contrary, as their borders are flowing, what actually happens is a constant movement between these two poles. Systems or environments can only be referred to as "self-contained entities" for analytical purposes and depending on the point of observation one adopts when describing or analyzing a concrete phenomenon.

A third presupposition stems from the issue of complexity. As an environment is always defined in relation to a system, the environment must always be more complex than the System. Environmental complexity in relation to the system "can lead to the formation of (sub-)systems in each system, allowing it to approach with greater effectiveness the complexity of the environment" (Izuzquiza 1990: 159).

Starting from such presuppositions that are far from delineating a complete characterization of the complex relationship system/environment, it is suggested that Internet, in the context of the Digital Cities, is better characterized not as a new medium, but as a (sub-)system that acts as environment of information, communication and action for other (sub-)systems in the hybrid network of the Digital City.

Therefore, at the same time that it constitutes a (sub-)system in the hybrid network, Internet also functions as shared environment (of communication, information and action) for a multiplicity of other (sub)systems and, evidently, for human actors (cognitive agents) or psychic systems, to use Luhmann's terminology.

Constituting an environment of information, communication and action for a multiplicity of distinct (sub-) systems, and as a result of that multiplicity and heterogeneity, Internet makes possible the co-existence, side by side within the complex network, of informational environments (databases of the most varied types), journalistic environments (online newspapers, online radios, news agencies), educational environments (online courses, specialized discussion lists, educational simulations, online libraries), interaction and communication environments (chats, forums, electronic mail), leisure and cultural environments (online games, museums), service environments (banks, sites for online tax declarations, investment advise), commercial environments (electronic malls and shops), work environments, and so on.

A characterization of Internet as both System and Environment allows one to go beyond the notion of mediation without discarding it. Thus for instance when a site primarily seen as "media", as in the case of a digital radio, is accessed, it reproduces via Internet, the program grid that is simultaneously broadcasted "live" through Hertzian waves, but also complements it with audience forums, mechanisms for the online purchase of advertised goods, access to sound and image archives, and other facilities. We are dealing with multiple and heterogeneous environments (of information, communication and action) juxtaposed in the same support (Internet), in which Dominique Wolton's logic of demand and the logic of offer can be said to co-exist side by side.

The heterogeneity and the multiplicity of functions one detects when analysing Internet become comprehensible when we look at them from the standpoint of the logic of operation of other (sub-)systems of society that use Internet as an important element of their environments and not, inversely, from the standpoint of Internet as a system and a medium.

To the extent that Internet is characterized by its situation of shared environment to multiple (sub-) systems, the diversification of functions observed may be interpreted as deriving from specific demands of the various (sub-)systems involved in a particular network, in a particular moment or situation. This leads, for instance, to the creation of specific software applications, that later on may be appropriated and used by other (sub-)systems. For instance, a software application that originates from specific demands of the financial (sub-)system (banking), to respond to the need to accomplish fast data transfers in electronic transactions, can afterwards (and very quickly) be incorporated in sites and activities of other (sub- 
)systems, and used for activities of a completely different nature and scope, as in education, journalism, and other types of virtual insertion.

The simultaneous use of Internet as an environment by a multiplicity of (sub-)systems puts differentiated and combined pressures in terms of its evolution, since multiple demands generate specific solutions that tend to be diffused and generalized to the totality of the network, being incorporated in the practices and activities of other (sub-)systems. It is in this sense that, as suggested by authors like Lévy (1997), Stockinger (2001), and others, "the Net lives"9 . Or at least, if one prefers to avoid such a direct biological metaphor, "the Net thrives"...

The widespread and seemingly simplistic idea that "one can find anything in the Net", reflects that situation of a shared environment. The characterization of Internet as sub-system and environment in a hybrid network allows one to picture it as a (quasi)autonomous social being, endowed with its own operational dynamics and evolution patterns and, at the same time, responding to the combined demands exerted on it by the (sub)systems that use it as environment. It becomes obvious how limited the characterization of Internet as nothing else but a technological support and mediation element is.

The aim and scope of this paper was to preliminarily suggest that a characterization of Internet based on the conceptual pair system/environment coupled with Bardini's model for hybrid networks, may provide a fruitful alternative to narrower views based solely on a mediation approach. It is thus proposed that the development of theoretical models anchored on the suggested pair of concepts, in the perspective sketched along this paper, can lead to a better characterization of the nature of the Internet. A refinement of such characterization and a more accurate delimitation of the role of Internet in the construction and management of any type of complex application/project in cyberspace, - as in the case of Digital Cities which constitute the main phenomenon under scrutiny in the ongoing research in which this paper originated -, is a necessary step in the direction of furthering our understanding and fruitful uses of the social potentialities of the New Technologies of Communication in contemporary society.

9 "and so does Elvis...", adds Stockinger (2001) in a light vein... 


\section{References}

ADCP (2000) Aveiro Digital City Project, available online: http://www.aveiro-digital.pt

Aurigi, Alessandro/Grahan, Stephen (1998) The Crisis in the urban public realm. In: Loader, B.D. (ed.) 1998. Cyberspace Divide:

Equally, Agency and Policy in the Information Society- London. Routledge.

Bardini, Thierry (1996) Changement et réseaux socio-techniques : de l' inscription à l' affordance, in : Reseaux, n. 76, CNET.

Branco, Vasco/Mamede, José (2002) Articulações entre a cidade e a Web: Considerações sobre as naturezas digital e mediática das Cidades Web portuguesas, Comunicarte, vol. 1, n.2, Aveiro.

Castells, Manuel (1998) End of Millenium. Massachusetts. Blackwell.

Chandler, Daniell (1995) The Act of Writing. Aberystwyth. The University of Wales, available online: http://www.aber.ac.uk/media/Documents/act/act-of-writing.doc

Chandler, Daniell (1995) Technological or Media Determinism, available online: http://www.aber.ac.uk/media/Documents/tecdet/tecdet.html

Ebersole, Samuel (1995) Media Determinism in Cyberspace, available online: http://www.regent.edu/acad/schcom/rojc/mdic/md.htm Fidalgo, Antonio (2001) Metáfora e realidade ou cooperação e concorrência na rede, available online: http://www.,cocc.ubi.pt, maio.

Flichy, Patrice (2001) L'imaginaire d'Internet. Paris. Éditions la Découverte.

Gobal Reachs (2000) Global Statistics, available online: http://www.glreach.com/globstats

Graham, Stephen/Marvin, Simon (2000) Planning Cyber-Cities? Integrating Telecommunications. in: Urban Planning. In: Town

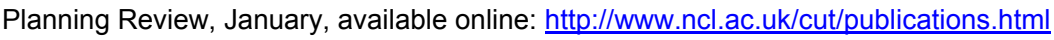

Guédon, Jean-Claude (1998) Au-delà de l'extase et de l'effroi: Internet et la reconstruction du citoyen, available online: http://www.cybersciences.com/cyber/1.0/1 29 Menu.htm

Ishida, Toru (2000) Understanding digital cities. In: Ishida, Toru/Isbister, Katherine (Eds.) (2000) Digital cities: experiences, technologies and future perspectives, Lecture notes in computer science, Vol. 1765. Berlin. Springer-Verlag, available online: http://www.digitalcity.jst.go.jp/pubs/select-e.html.

Izuzquiza, Ignaci (1990) La Sociedad sin Hombres: Niklas Luhamann o la teoria como escándalo. Barcelona. Anthropos.

Kitchin, Rob (1998) Cyberspace. Chichester. John Wiley \& Sons.

Lemos, André (2001) Cibercidades. in: Lemos, André/Palacios, Marcos (Eds.) (2001) Janelas do Ciberspaço. Porto Alegre. Sulina. Lemos, André (2001b) Das Cidades Digitais às Micronações Virtuais. Cidadania Digital e Cibercultura, Paper presented at the I Colóquio Internacional sobre Redes e Cibercidades, Salvador, November.

Lévy, Pierre (1997) Cyberculture. Paris. Éditions Odile Jacob.

Lévy, Pierre (2000) World Philosophie. Paris. Éditions Odile Jacob.

Loader, Brian (Eds.) (1998) Cyberspace Divide: Equality, Agency and Policy in the Information Society. London. Routledge.

Loureiro da Silva, Lídia de Jesus Oliveira (2002) Implicações Cognitivas e Sociais da Globalização das Redes e Serviços Telemáticos: estudo das implicações da comunicação reticular na dinâmica cognitiva e social da Comunidade Científica Portuguesa, Ph. Thesis, Departamento de Comunicação e Artes, Universidade de Aveiro, Portugal.

Luhmann, Niklas (1992) A Improbabilidade da Comunicação. Lisboa. Vega.

Maldonado, Tomás (1998) Crítica de la Razón Informática. Barcelona. Paidós.

MCT (2000) Sociedade da Informação no Brasil: Livro Verde, Brasília, available online: (http://www.socinfo.org.br)

MSI/MCT (1997) Sociedade da Informação: Livro Verde para a Sociedade da Informação em Portugal, Lisboa, available online: (http://www.missao-si.mct.pt)

Millarch, Francisco (1998) Net Ideologies: from Cyber-Liberalism to Cyber-Realism. In: Cybersoc Magazine, Issue 4, December, available online: $\mathrm{http}: / /$ members.aol.com/Cybersoc/issue4.html

Morris, Merril/Ogan, Christine (1996) The Internet as Mass Medium. In: Journal of Computer Mediated Communication, No. 4, available online: http://www.ascusc.org/jcmc/vol1/issue4/cover.html

Neves, Fernando Santos (Ed.) (2000) A Globalização Societal Contemporânea e o espaço Lusófono: Mitideologias, Realidades e Potencialidades. Lisboa: Edições Universitárias Lusófonas.

NUA - New Thinking for the Digital Age (2000) Internet Surveys, available online: http://www.nua.ie/surveys/ (2000)

Palacios, Marcos (2001) Por Mares Doravante Navegados. In: Lemos, André/Palacios, Marcos (Eds.) Janelas do Ciberspaço. Porto Alegre. Sulina.

Palacios, Marcos (2001b) Internet e Televisão, in: Correio Brasiliense, 16th. September, available online: http://www2.correioweb.com.br/cw/2001-09-16/mat 12769.htm

Palacios, Marcos (2002a) Mito e Potencia das Cibercidades, in: Correio Brasiliense,available online: http://www2.correioweb.com.br/cw/2001-09-16/mat 12769.htm

Palacios, Marcos (2002b). Jornalismo Online, Informação e Memória: Apontamentos para discussão. Paper presented at the Workshop de Jornalismo Online, Universidade da Beira Interior, Covilhã, Portugal, june, available online: http://www.facom.ufba.br/jol/producao.htm 
Parsons, Talcott (1974) O sistema das sociedades modernas. São Paulo. Pioneira (The system of modern societies, Prentice Hall, 1971)

Piette, Jacques (1998) Nouvelles technologies pour quelle citoyenneté, available online : http://www.ac-dijon.fr/ouvint/d-ouv059.htm Ritzer, George (1996) La MacDonalización de la sociedad: Un análisis de la racionalización en la vida cotidiana. Barcelona. Ariel Sociedad Econónima.

Selber, Samuel (1995) Technical Writing in a Technological Age: Changes in the Classroom and the Workplace, available online: http://longman.awl.com/englishpages/tech activ tech.htm

Spalding, Steve (1999) Travels in Theoretical Spaces: Deleuze, Guattari and Foucault, available online: http:// www.gradnet.de/pomo2.archives/pomo99.papers/Spalding99.htm

Schwartz, Gilson (2001) Apontamentos sobre o segundo encontro de Kyoto sobre cidades digitais, available online: http://www.usp.br/iea/cidade/kyoto2.html.

Stockinger, Gottfried (2001) Para uma sociologia da comunicação, available online: http://www.facom.ufba.br/sociologia da com.doc 